\section{Recurrent symptoms following traumatic corneal abrasion: prevalence, severity, and the effect of a simple regimen of prophylaxis}

TOM EKE, DANNY A. MORRISON, DAVID J. AUSTIN

\begin{abstract}
Purpose (i) To describe the course of ocular symptoms and recurrent corneal erosion (RCE) following traumatic corneal abrasion (TCA). (ii) To assess the efficacy of a regimen of nightly eye ointment in preventing symptoms and RCE.

Methods Patients presenting with TCA were treated with g. cyclopentolate $1 \%$ stat. and oc. chloramphenicol q.d.s. for $\mathbf{5}$ days. Eye pads were not used. For injuries caused by a fingernail, patients were randomised to receive either this 'standard regimen' alone, or to follow with a lubricating ointment (Lacrilube) nocte for $\mathbf{2}$ months. Follow-up was by telephone, using a symptom-based questionnaire. Recurrent symptoms were graded as: (i) none or minimal, (ii) mild, (iii) moderate (difficulty with some activities, or sought further opinion) and (iv) disabling (confirmed macroform RCE). After 2 years, case-notes were reviewed. The study is continuing, with further telephone follow-up taking place.

Results Three-month follow-up was completed for 42 'fingernail' injuries and 32 'non-fingernail' TCAs. When treated with our standard regimen, 'mild' symptoms were reported in $10 \%$ of 'fingernail' and $10 \%$ of 'non-fingernail' injuries. Symptoms were 'moderate' in 0 and $12 \%$ respectively. Chisquared test confirmed a significantly higher prevalence of recurrent symptoms in the 'additional nightly ointment' group of 'fingernail' injuries $(p=0.016)$. Two macroform RCEs were confirmed by 2 years: one from each treatment group of 'fingernail' injury. Conclusions When TCA is managed as above, there is a high prevalence of recurrent symptoms in the following 3 months. Additional nightly ointment appears to worsen prognosis. Macroform RCE is not common in the 2 years following TCA.
\end{abstract}

Key words Traumatic corneal abrasion, Recurrent corneal erosion, Epithelium - corneal, Eye injuries, Recurrence, Symptoms

Traumatic corneal abrasion (TCA) is one of the commonest causes of attendance in Eye Casualty and General Accident and Emergency departments. ${ }^{1}$ Surprisingly for such a common condition, there is no agreed management protocol for the acute condition. ${ }^{2}$ While simple treatment regimens have been shown to give good short-term healing, ${ }^{3,4}$ no previous study has assessed symptoms once the initial TCA lesion has healed.

It is known that a proportion of eyes with TCA will later suffer from recurrent corneal epithelial erosion (RCE), a painful and distressing condition which may become chronic despite treatment. Patients with RCE may describe ocular pain on awakening, photophobia, watering, foreign body sensation/ grittiness or discomfort. ${ }^{5-7}$ There is a longstanding clinical impression that abrasions caused by a fingernail, particularly a baby's fingernail, are more likely to progress to RCE. ${ }^{3,5,6}$ RCE has been classified into 'microform' (intraepithelial microcysts with a minor break in the epithelium, generally causing relatively minor symptoms) and 'macroform' (where a large area of epithelium separates from the cornea, resulting in extreme pain which lasts for hours or days). ${ }^{5}$ Clinical experience suggests that macroform RCE is uncommon following TCA, and this has been borne out by some short-term follow-up studies. ${ }^{3,4}$ Many patients presenting with macroform RCE describe having had a TCA followed by chronic recurrent symptoms which are suggestive of microform RCE. Despite this, no published study has specifically looked at less severe recurrent symptoms following TCA.
T. Eke

D.A. Morrison

D.J. Austin

Department of

Ophthalmology

Leicester Royal Infirmary

Leicester, UK

Mr Thomas Eke, MA,

FRCOphth

Department of

Ophthalmology

Leicester Royal Infirmary

Leicester LE1 5WW, UK

This work was presented as a poster at the Oxford

Ophthalmological Congress, July 1998

The authors have no proprietary interests relevant to this paper

Funding: Allergan Ltd provided Lacrilube ointment free of charge, and contributed towards the costs of the telephone survey

Received: 29 July 1998 Accepted in revised form: 20 January 1998 
Table 1. Prevalence and severity of recurrent symptoms 3 months after treatment for traumatic corneal abrasion

\begin{tabular}{|c|c|c|c|c|}
\hline $\begin{array}{l}\text { Cause of injury } \\
\text { Treatment group } \\
\text { No. of patients }\end{array}$ & $\begin{array}{l}\text { No symptoms } \\
\text { or minimal } \\
\text { symptoms }\end{array}$ & $\begin{array}{c}\text { Mild } \\
\text { symptoms } \\
\text { (non-disabling) }\end{array}$ & $\begin{array}{l}\text { Moderate symptoms } \\
\text { (difficulty with daily activities, } \\
\text { or sought further opinion) }\end{array}$ & $\begin{array}{c}\text { Severe symptoms } \\
\text { (confirmed macroform } \\
\text { recurrent corneal erosion) }\end{array}$ \\
\hline $\begin{array}{l}\text { Fingernail } \\
\text { Standard regimen (see text) } \\
n=20\end{array}$ & $\begin{array}{c}17 \\
(85 \%)\end{array}$ & $\begin{array}{c}2 \\
(10 \%)\end{array}$ & 0 & $\begin{array}{c}1 \\
(5 \%)\end{array}$ \\
\hline $\begin{array}{l}\text { Fingernail } \\
\text { Additional nightly ointment } \\
\text { (see text) } \\
n=22\end{array}$ & $\begin{array}{c}11 \\
(50 \%)\end{array}$ & $\begin{array}{c}7 \\
(32 \%)\end{array}$ & $\begin{array}{c}4 \\
(18 \%)\end{array}$ & 0 \\
\hline $\begin{array}{l}\text { Other causes } \\
\text { Standard regimen } \\
n=32\end{array}$ & $\begin{array}{c}25 \\
(78 \%)\end{array}$ & $\begin{array}{c}3 \\
(10 \%)\end{array}$ & $\begin{array}{c}4 \\
(12 \%)\end{array}$ & 0 \\
\hline
\end{tabular}

Symptoms were assumed to be due to recurrent corneal erosion if they were described as frequent and significant pain, grittiness, photophobia or watering of the injured eye only. ${ }^{6}$

Patients may suffer repeated attacks of macroform $\mathrm{RCE}$, and various treatments have been assessed as secondary prevention in established RCE syndrome..$^{7-10}$ One of the simpler treatments advocated to prevent further attacks is the nightly use of a topical eye ointment. ${ }^{11,12}$ Our study set out to assess whether nightly topical ointment would be useful as a primary treatment after TCA. We hoped that this treatment would prevent the development of RCE following TCA.

The study set out to answer the following questions:

1. What is the 'natural history' of symptoms following

TCA? What proportion of patients have recurrent symptoms following TCA? What is the incidence of 'macroform' RCE? What is the time period between TCA and RCE?

2. Are TCA injuries caused by a fingernail really at higher risk of developing RCE?

3. Does topical ointment prevent the development of RCE in patients who have had TCA?

\section{Method}

This is a prospective study of symptoms following TCA, with the 'fingernail' injuries randomised to one of two treatment groups. The study has the approval of our local Research Ethics Committee, and all patients gave their informed consent. Patients were recruited from the Eye Casualty unit at Leicester Royal Infirmary, which offers a self-referral service during office hours. All patients presenting with TCA in a previously healthy eye were treated with a standard regimen of $\mathrm{g}$.

cyclopentolate $1 \%$ stat. and oc. chloramphenicol q.d.s. for 5 days; eye pads were not used. ${ }^{4}$ Patients were excluded from the study if they had any previous ocular pathology, wore contact lenses, had diabetes, were aged under 16 years, or for any reason were unable to participate in follow-up by telephone. Injuries caused by a fingernail were randomised to one of two treatment groups. One group received the 'standard regimen' alone, whilst the other continued with a 'prophylactic regimen $^{7,8}$ of lubricating ointment (Lacrilube, Allergan) nocte for 2 months.
Patients were followed up 3 months after the initial injury by telephone, using a symptom-based questionnaire. Symptoms were assumed to be due to the initial injury if they were described as frequent and significant pain, grittiness, photophobia or watering of the injured eye only. ${ }^{6}$ Recurrent symptoms were graded as: (i) none or minimal, (ii) mild, (iii) moderate (difficulty with some daily activities, or sought further advice from a health professional) and (iv) severe (macroform recurrent erosion confirmed on examination). Case-notes were reviewed at 2 years. Results were analysed statistically using chi-squared test. The study is continuing, with further telephone follow-up to take place at 3 years.

\section{Results}

Seventy-four patients completed the 3-month follow-up questionnaire (Table 1). In 42 cases, the injury was caused by a fingernail. At 3 months there was a high prevalence of symptoms suggestive of RCE. A total of 21 patients $(28 \%)$ reported frequent and significant pain, grittiness, photophobia or watering of the injured eye only.

We found no significant difference in overall symptom prevalence between 'fingernail' and 'nonfingernail' injuries which had been managed with our standard regimen (chi-squared test: $p=0.54$ ). Severity of symptoms was broadly similar in these two groups (see Table 1). For injuries caused by a fingernail, the use of additional nightly ointment was associated with a higher prevalence of symptoms at 3 months (significant to chisquared test, $p=0.016$ ). By 2 years, two patients, both with 'fingernail' injuries, had presented to us with macroform RCE: the first was 3 months after TCA treated with the 'standard' regimen, the other 7 months after TCA treated with additional nightly ointment.

\section{Discussion}

TCA in otherwise healthy eyes is associated with a high prevalence $(28 \%)$ of current symptoms in the first 3 months. Nine patients in our study $(12 \%)$ reported symptoms which interfered with some daily activities, or 
led them to seek advice from Eye Casualty, general practitioner or pharmacist. The reasons why these patients did not all re-attend Eye Casualty were not explored in our questionnaire, but we suspect that this was due to a combination of factors, including the transient nature of the symptoms.

We found the incidence of the disabling 'macroform' $\mathrm{RCE}$ to be of the same order as other studies. ${ }^{3,4}$ By 2 years, macroform erosion had been diagnosed in 2 of 42 (5\%) of the 'fingernail' injury group and 0 of 32 of those with TCA from other causes. The numbers are too small for us to be certain whether the nature of the injury has a significant effect, but this may become more apparent as the study progresses. It is possible that further patients had a macroform RCE during the 2 years but were not assessed in our unit. Information regarding this will become available with the next round of telephone follow-up.

Prophylactic topical nightly ointment does not prevent recurrent symptoms in the initial months. Instead, the reverse seems to be true. For patients whose injury was caused by a fingernail, symptoms were significantly more prevalent $(p=0.016)$ and more severe in the group receiving additional ointment. It will be interesting to see whether this effect is maintained at 3-year follow-up. The use of additional nightly ointment did not appear to have any effect on the incidence of macroform RCE by 2 years, but the small numbers and possible incomplete data capture preclude us from drawing a firm conclusion.

There are several possible explanations for the high prevalence of recurrent symptoms in our patients. It may be that in our initial management, the use of ointment or movement of the unpadded lid interfered with healing, and resulted in small areas of poorly adherent epithelium. The high prevalence of symptoms suggests we should consider changing our initial treatment regimen: a randomised trial comparing pad/no pad/soft contact lens, and antibiotic drops/ointment would be of great interest. We await the result of our further followup before planning such a study.
This is an early report from a continuing study. The unexpected results challenge the preconceptions that patients are generally symptom-free within days of TCA, and that nightly ointment is of symptomatic benefit. Our results also demonstrate that any future evaluation of treatment for TCA should include a follow-up of patient symptoms.

We are grateful to Dr John Thompson for statistical advice. The Lacrilube ointment was kindly provided by Allergan Ltd.

\section{References}

1. Jones NP, Hayward JM, Khaw PT, Claoué CMP, Elkington AR. Function of an ophthalmic 'accident and emergency' department: results of a six month survey. BMJ 1986;292: 188-90.

2. Sabri K, Pandit JC, Thaller VT, Evans NM, Crocker GR. Current management of corneal abrasions: evidence based practice? Br J Ophthalmol 1997;81:1116-7.

3. Jackson H. Effect of eye-pads on healing of simple corneal abrasions. BMJ 1960;II:713.

4. Kirkpatrick JNP, Hoh HB, Cook SD. No eye pad for corneal abrasion. Eye 1993;7:468-71.

5. Chandler PA. Recurrent erosion of the cornea. Am J Ophthalmol 1945;28:355-63.

6. Brown N, Bron A. Recurrent erosion of the cornea. Br J Ophthalmol 1976;60:84-95.

7. Buxton JN, Fox ML. Superficial epithelial keratectomy in the treatment of epithelial basement membrane dystrophy. Arch Ophthalmol 1983;101:392-463.

8. McLean EN, MacRae SM, Rich LF. Recurrent erosion: treatment by anterior stromal puncture. Ophthalmology 1986;93:784-7.

9. Geggel HS. Successful treatment of recurrent corneal erosion with Nd:YAG anterior stromal puncture. Am J Ophthalmol 1990;110:404-7.

10. Bernauer W, De Cock R, Dart JKG. Phototherapeutic keratectomy in recurrent corneal erosions refractory to other forms of treatment. Eye 1996;10:561-4.

11. Hykin PG, Foss AE, Pavesio C, Dart JKG. The natural history and management of recurrent corneal erosion: a prospective randomised trial. Eye 1994;8:35-40.

12. Heyworth P, Morlet N, Rayner S, Hykin P, Dart J. Natural history of recurrent erosion syndrome: a 4 year review of 117 patients. Br J Ophthalmol 1998;82:26-8. 